\title{
The rise and fall of mantle plumes
}

Mantle plumes give rise to some of the most volcanically active regions on Earth (such as Hawaii) and represent a key component of planetary dynamics. Deep-seated plumes are typically associated with the margins of two large low shear velocity provinces (LLSVPs) at the core-mantle boundary (CMB). LLSVPs are believed to represent piles of recycled crustal material, or magma ocean cumulates. However, the mechanism of plume initiation at LLSVP boundaries, and the role that these deep-mantle structures have on plume-dynamics remains highly uncertain.

Björn Heyn from the University of Oslo, Norway, and colleagues, investigated the link between LLSVPs and mantle plumes using 2D numerical models of mantle convection. Simulations reveal the presence of a 'plume cycle', where mantle upwelling is generated by a collapse of the LLSVP margin. Gravitational collapse typically occurs after over-thickening of the LLSVP

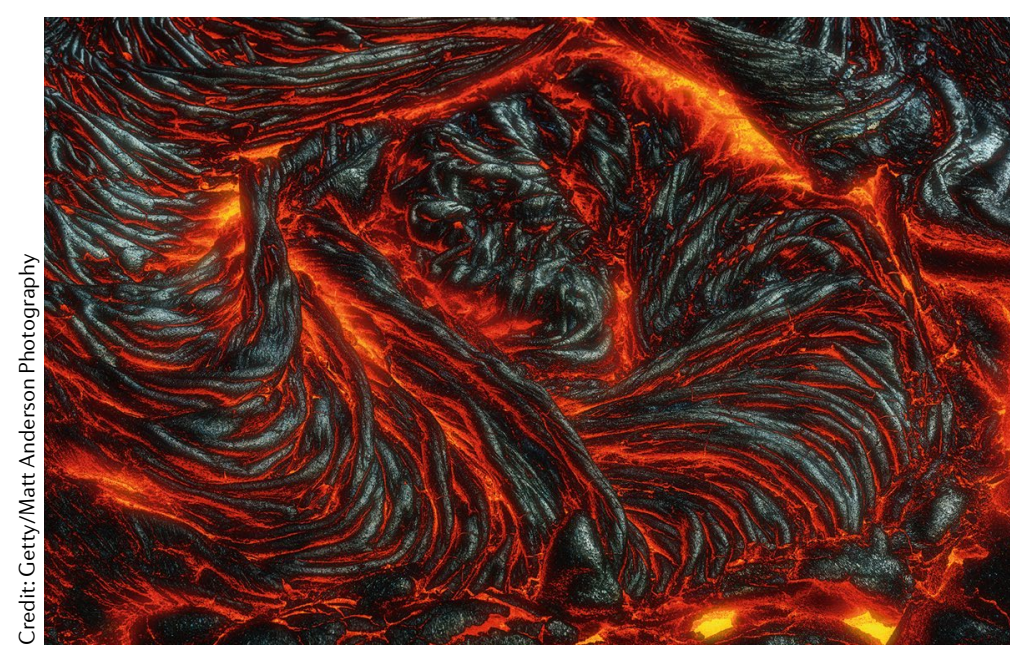

margin, owing to the presence of an earlier plume, followed by cooling and cessation in the upward pull of the plume material. Subsequent spreading of the LLSVP margin along the $\mathrm{CMB}$ leads to a local widening of the thermal boundary layer, increasing the probability of initiating a new plume. As a result, cyclic behaviour in the rise and fall of plumes from LLSVP margins is predicted.

Although simulations can recreate the spatial association between mantle plumes and LLSVP margins, the lack of geochemical data for plume-derived volcanism older than 200 Ma precludes the identification of plume cyclicity in nature. Nevertheless, generation of mantle plumes from collapsed LLSVP margins could explain several key features of plume-derived volcanism, such as the temporal and spatial clustering of large igneous provinces, and thus mantle plumes, along the margins of LLSVPs.

Matthew Gleeson

ORIGINAL ARTICLE Heyn, B. et al. How thermochemical piles can (periodically) generate plumes at their edges.JGR Solid Earth https:// doi.org/10.1029/2019JB018726 (2020) 